\title{
The Possibilities of Fission Material Reproduction Increase in Thermal Reactor with the Assemblies with a Hard Neutron Spectrum
}

\author{
Vladimir M. Kotov, Anna S. Sergeeva, Ruslan A. Irkimbekov, and Vladislav I. Suprunov \\ Institute of Atomic Energy, NNC RK, 071100 Kurchatov, Kazakhstan \\ Correspondence should be addressed to Vladimir M. Kotov, kotovvm@nnc.kz
}

Received 20 May 2011; Revised 26 August 2011; Accepted 22 September 2011

Academic Editor: Keith E. Holbert

Copyright ( $) 2011$ Vladimir M. Kotov et al. This is an open access article distributed under the Creative Commons Attribution License, which permits unrestricted use, distribution, and reproduction in any medium, provided the original work is properly cited.

This paper addresses the problem of fission material reproduction increase in thermal reactors. Reproduction increase is achieved while decreasing the fission material content in the fuel. In that case, a decrease of neutron loss in construction materials and a neutron leakage decrease are required for obtaining reactor criticality. Effectiveness of the reactor functioning can be increased by the use of additional neutron sources, for example, $n-2 n$ reaction in beryllium framing. The possibility of additional neutron source development with the use of fast neutrons with an energy distribution close to the fission spectrum in the major part of thermal reactor core is researched in this paper.

\section{Introduction}

The actual task of nuclear engineering is the increasing of the ratio of produced nuclear energy to energy produced by combustible fuel. Existing thermal reactors with uranium fuel consume a small part of the raw uranium and it is not a solution of the task because of the small stock of raw uranium.

Fast neutron reactors allow building of effective power engineering in relation to uranium usage, but they need enormous initial amounts of raw uranium to start with further adding to enrichment industry wastes $[1,2]$. Large amounts of fission material reprocessing, which is needed in the technology of fast reactors, cause, technical and economical problems and increase proliferation risks of fission material [3].

In Institute of Atomic Energy of NNC RK, the possibility of large-scale nuclear power engineering creation without these problems is considered. The solution is based on usage of thermal reactors with high fission material reproduction, which is achieved by minimizing neutron losses in construction materials, the use of additional neutron sources, and other means. Different core designs are studied. It shows positive results and high potential possibilities of the chosen research direction.

Raw uranium usage in the proposed fuel cycle is up to $20-30 \%$ in better designs. The full raw uranium usage can be achieved in variants with additional sources, but it causes losses of produced energy [4]. Usage effectiveness of external neutron source, which is based on thermonuclear reactions, is shown [5]. In that paper the possibility of obtaining additional neutrons in thermal channel reactor due to increase of average neutron energy in some parts of the fuel assemblies is researched.

\section{Reactor Design and Basic Elements of Fuel Assembly}

Heavy water is the moderator in the proposed reactor. The reflector is made of a heavy water layer surrounded by a graphite layer.

The major part of the core consists of 636 "common" fuel assemblies and 12 fuel assemblies with a hard spectrum (Figure 1). 


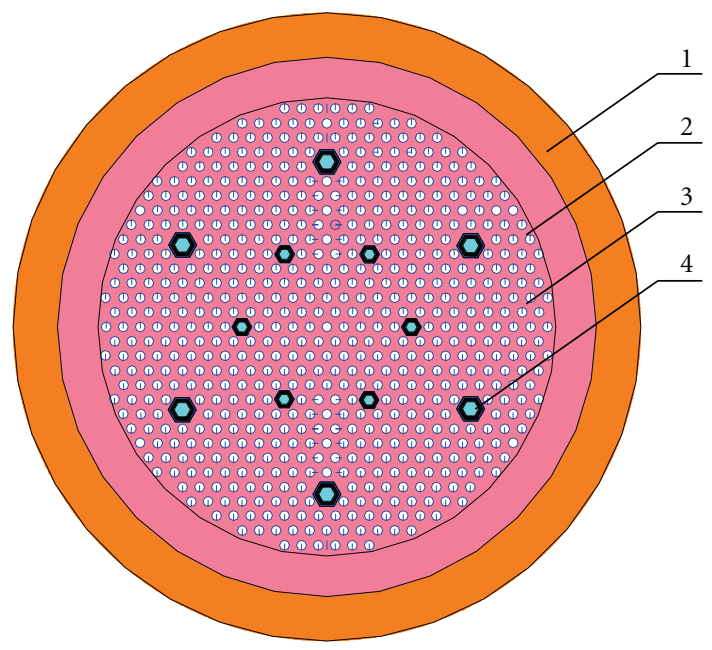

FIgURE 1: Core design with hard spectrum fuel assemblies surrounded by fuel assemblies with thermal spectrum. 1: graphite reflector, 2: heavy water moderator and reflector, 3: fuel assemblies with thermal spectrum, 4: fuel assemblies with hard spectrum.

Each thermal assembly contains 20 fuel rods with diameter $4 \mathrm{~mm}$, located at the same radius relating to fuel assembly center. It means that all fuel rods are in the same thermalhydraulic conditions and neutron spectrum (Figure 2).

A higher number of fuel rods with diameter $3 \mathrm{~mm}$ (up to 1140 rods in variant with full load) is used for fuel assembly with the hard spectrum. Reducing the number of fuel rods is made by pulling rods from the fuel assembly center and filling the space with gas that weakly absorbs and weakly moderates neutrons (Figure 3). Filling the space with gas allows spreading fast neutrons to all fuel rods of the hard of the spectrum fuel assembly.

Between the core heavy water and fuel rods of the hard spectrum assembly there is a heavy metal layer, which prevents thermal neutron migration to this assembly and allows reflection of fast neutrons, which were born in it. Thickness of the metal layer is about $2-4 \mathrm{~cm}$. This layer can be made of $\mathrm{Bi}, \mathrm{Pb},{ }^{120} \mathrm{Sn}$, or their mixture.

\section{Calculation Results}

Processes in the hard spectrum fuel assembly, which begin from the border between the heavy water and heavy metals, are complex enough. All calculations are made in MCNP-5 [6]. Sufficient trustworthiness of the calculations is reached at a number of histories not less than 100000 .

Sensitivity for the following parameters was researched:

(1) fuel composition;

(2) neutron spectra in assemblies with thermal and hard neutron spectra;

(3) heavy metal layer thickness between moderator and fuel rods of assembly with hard spectrum;

(4) energy release radial distribution in assembly with hard spectrum;

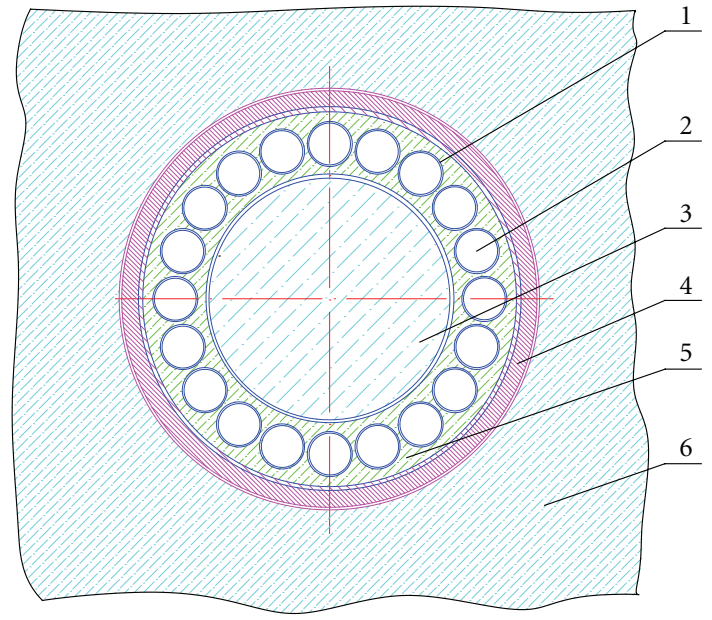

Figure 2: Thermal neutron fuel assembly. 1: zirconium shell, 2: thermal neutron fuel, 3: gaseous region, 4: fuel assembly case, 5: coolant, 6: moderator.

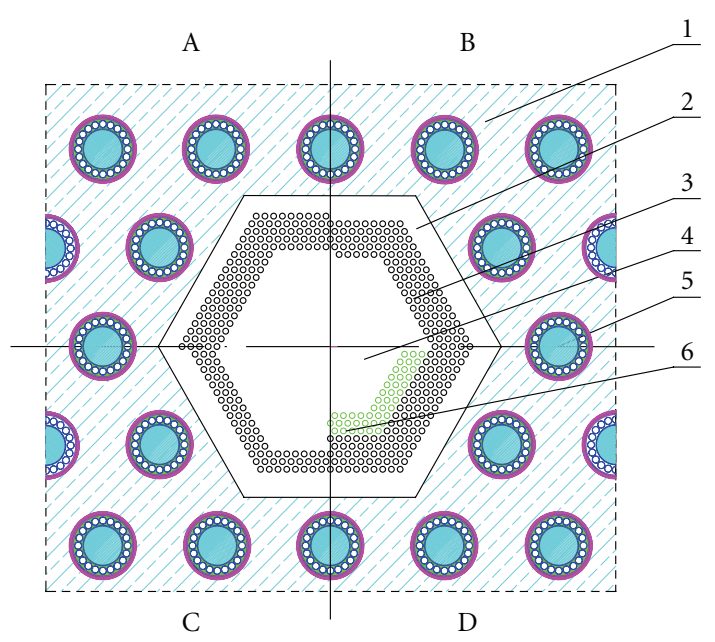

FIGURE 3: Variants of hard assembly (A) with heavy metal layer thickness, $2 \mathrm{~cm}$ and 5 rows of fuel rods, (B) with layer thickness, $3 \mathrm{~cm}$ and 5 rows of fuel rods, (C) with layer thickness, $3 \mathrm{~cm}$ and 8 rows of fuel rods, (D) with layer thickness, $3 \mathrm{~cm}$ and 3 rows of fuel rods. 1: heavy water moderator, 2: heavy metals layer, 3: peripheral fuel rods of the assembly with hard spectrum, 4: gaseous region (middle part of the assembly), 5: fuel assembly with thermal neutron spectrum, and 6: central fuel rods.

(5) complete filling of central region of the assembly with fuel rods;

(6) fission material contents in assemblies with thermal and hard neutron spectra.

All calculation variants are made with two types of fuel, different by actinide inventory. In the first variant the fuel contains ${ }^{238} \mathrm{U}$, thorium and fissile materials on its base${ }^{233} \mathrm{U},{ }^{239} \mathrm{Pu}$, the second variant fuel contains ${ }^{238} \mathrm{U}$ and ${ }^{239} \mathrm{Pu}$ (Table 1).

Calculation of the average contents of fission materials in campaign of this reactor is correct when the multiplication constant is close to unity $\left(k_{\text {eff }} \geq 1\right)$. 


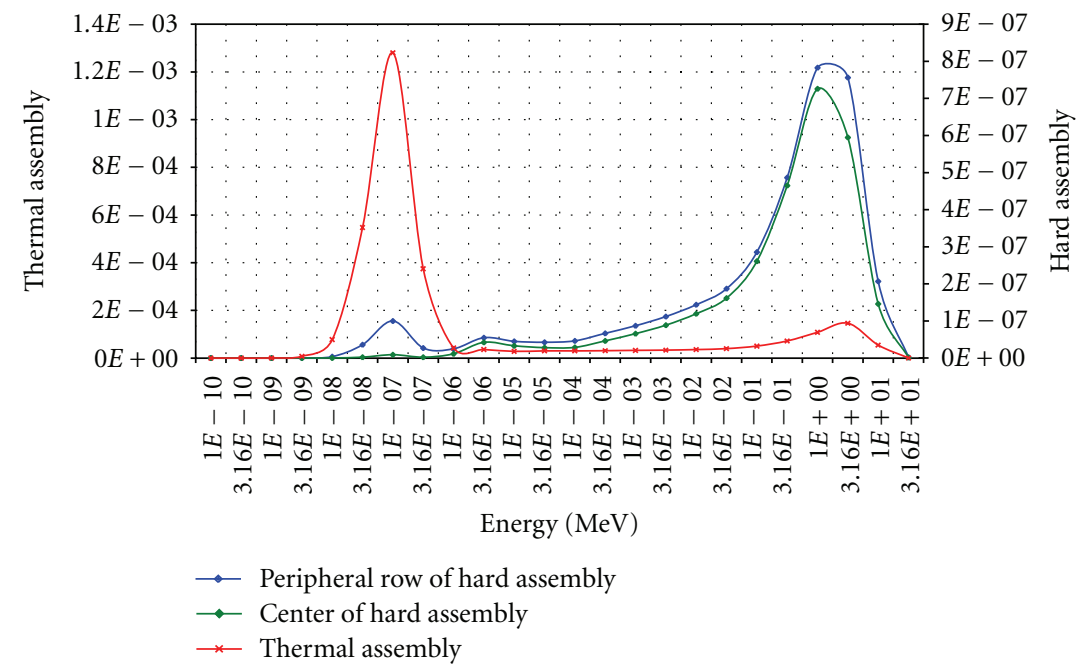

FIGURE 4: The relative neutron spectra in the thermal assembly, in the peripheral and the central rods of the hard assembly.

TAble 1: Percentage of fuel materials in fuel rods using mass contents.

\begin{tabular}{lcccc}
\hline \multirow{2}{*}{ Nuclide } & \multicolumn{2}{c}{ Variant 1 } & \multicolumn{2}{c}{ Variant 2 } \\
& Hard & Thermal & Hard & Thermal \\
\hline${ }^{232} \mathrm{Th}$ & 22.5 & 24.5 & - & - \\
${ }^{238} \mathrm{U}$ & 76.5 & 73.5 & 90 & 99.8 \\
${ }^{239} \mathrm{Pu}$ & 0.65 & 0.13 & 10 & 0.2 \\
${ }^{233} \mathrm{U}$ & 0.35 & 0.07 & - & - \\
\hline
\end{tabular}

The neutron spectrum calculation for both fuel variants is carried out. The neutron spectra in the fuel rods of the thermal assemblies are almost the same. Neutron spectra in the fuel rods of the assembly with hard neutron spectrum are different. Figure 4 shows spectra in the fuel rods of the thermal assembly, in peripheral fuel rod rows of assembly with hard spectrum, and in the central fuel rod rows of assembly with hard spectrum, as shown at Figure 3(D).

The fuel neutron spectrum of the thermal assemblies is thermal. In the peripheral row of the hard spectrum assembly there is some rise in thermal energy range, but the highest peak is at energy close to fission neutron energy. In the central rods of the assembly with hard spectrum the peak is significantly decreased, while the fast neutron peak is almost the same. In the central fuel rods of assemblies with a hard spectrum, the amount of thermal neutrons is minimal.

The influence of the heavy metal layer thickness between moderator and hard spectrum assembly with key size $41 \mathrm{~cm}$ (Figures 3(A), and 3(B)) on the power of the hard spectrum assemblies, which is proportional to the ratio of the number of fissions in the hard spectrum assemblies $\left(N_{\text {ha }}\right)$ to the total number of fission in the reactor $\left(N_{r}\right)$ (Table 2$)$, was researched.

The influence of the number of fuel rod rows (Figures 3(B), 3(C), and 3(D)) in the hard spectrum assembly on the reproduction coefficient was also investigated. The central region is filled with gas. The variant with complete filling
TABle 2: Ratio of fissions in hard assemblies to total fissions in reactor with dependence on heavy metal layer thickness.

\begin{tabular}{lc}
\hline Layer thickness, cm & $N_{\mathrm{ha}} / N_{r}, \%$ \\
\hline 1.95 & 11.73 \\
2.95 & 5.69 \\
3.95 & 3.89 \\
\hline
\end{tabular}

TABLE 3: Characteristics of reactor and hard assembly with different heavy metal layers.

\begin{tabular}{lcccc}
\hline $\begin{array}{l}\text { Heavy metal } \\
\text { layer, } \mathrm{cm}\end{array}$ & $k_{\text {eff }}$ & \multicolumn{3}{c}{ Number of fissions in ${ }^{238} \mathrm{U}$ in rows, \% } \\
& & Peripheral & Interim & Central \\
\hline 1.95 & 1.14 & 8.02 & 2.61 & 1.10 \\
2.95 & 1.09 & 5.4 & 1.73 & 0.8 \\
3.95 & 1.07 & 2.61 & 0.87 & 0.41 \\
\hline
\end{tabular}

of the hard spectrum assembly with fuel rods was divided into three zones: peripheral: 324 fuel rods, interim: 421 fuel rods, and central: 396 fuel rods. Variants with different fission material contents were researched. In the outer rows, high contents of fission materials, in the interim, in average less contents of fission materials, and, in the central rows, low contents of fission material fuel up to zero (fuel rod imitators) were researched. It was determined that this solution allows increasing the number of fissions in raw nuclides and reproduction of fission materials.

Fission in the ${ }^{238} \mathrm{U}$ zone distribution shows that in the peripheral zone there is a high contribution of thermal neutrons from the thermal fuel assemblies (Table 3). The thick heavy metal layer causes a significant handicap to thermal neutron migration to the sink region (which is hard spectrum assembly). Results show that less thickness of heavy metal layer makes significantly higher multiplication constant $\left(k_{\text {eff }}\right)$. This result implies the possibility of reproduction coefficient increase in thermal assemblies by means of decreasing the fission material contents in it. 
TABLE 4: Dependence of the multiplication constant and the reproduction coefficient from fission material contents in fuel assemblies.

\begin{tabular}{lccr}
\hline \multirow{2}{*}{ No. of case } & \multicolumn{2}{c}{$\begin{array}{c}\text { Fission material contents in fuel assemblies, } \% \\
\text { Thermal spectrum }\end{array}$} & $k_{\text {eff }}$ \\
\hline 1 & Hard spectrum & 0.2 & 0.91 \\
2 & 5 & 0.2 & 0.99 \\
3 & 10 & 0.2 & 0.92 \\
4 & 15 & 0.2 & 1.21 \\
5 & 20 & 0.3 & 1.01 \\
6 & 20 & 0.5 & 1.02 \\
\hline
\end{tabular}

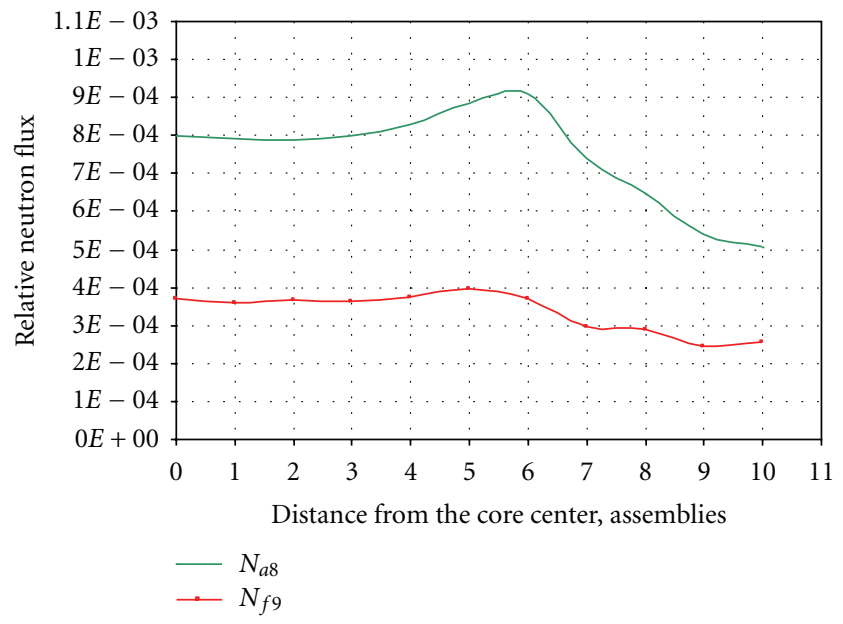

FIGURE 5: Radial distribution of neutron absorption in ${ }^{238} \mathrm{U}\left(\mathrm{N}_{a 8}\right)$ and fissions on ${ }^{239} \mathrm{Pu}\left(N_{f 9}\right)$.

The influence of fission material content in the hard spectrum assembly and the thermal assembly on the multiplication constant $\left(k_{\text {eff }}\right)$ and reproduction coefficient $\left(k_{\text {repr }}\right)$ was researched (Table 4 ).

The reproduction coefficient was calculated using the number of absorptions $\left(N_{a}\right)$ in ${ }^{238} \mathrm{U}$ and ${ }^{239} \mathrm{Pu}$, the number of fissions $\left(N_{f}\right)$ in ${ }^{239} \mathrm{Pu}$, and the multiplication constant $\left(k_{\text {eff }}\right)$ from the reactor calculations:

$$
k_{\text {repr }}=\frac{N_{a}^{238} \mathrm{U}}{N_{a}^{239} \mathrm{Pu}+N_{f}^{239} \mathrm{Pu}} \cdot k_{\text {eff. }}
$$

The radial energy release distribution in the reactor by number of fissions in ${ }^{239} \mathrm{Pu}$ in the thermal assemblies and distribution of neutron absorption in ${ }^{238} \mathrm{U}$ in these assemblies at horizontal reactor axis (Figure 1) are researched. Calculation results are shown in Figure 5. Nonuniformity of these distributions is not high.

\section{Conclusion}

The conducted calculations have shown creation possibility in thermal reactor of additional neutron source from fuel assemblies with neutron spectrum close to the fission neutron spectrum.

The spectrum formation in the additional (hard spectrum) fuel assemblies happens because of fission material content increase in its fuel rods and fuel assembly region separation from core moderator by layer of heavy metals with low neutron absorption cross-section.

The influence of the heavy metal layer thickness and fission material distribution in fuel rods of the hard assembly on the reactor characteristics was researched.

The possibility of increasing fission material reproduction coefficient in the suggested reactor is shown.

\section{References}

[1] E. O. Adamov, L. A. Bolshov, I. H. Ganev et al., "Belaya kniga atomnoi energetiki," Moscow, 270 p., 2001.

[2] N. N. Ponomarev-Stepnoy, P. N. Alexeev, V. D. Davidenko et al., "Comparison of development directions of nuclear energy in XXI century on the base of material balance," Atomnaya Energiya, vol. 91, no. 5, p. 331, 2001 (Russian).

[3] V. M. Kotov and S. V. Kotov, "Fission material reproduction in thermal reactors," Atomnaya Energiya, vol. 71, no. 5, p. 145, 2007 (Russian).

[4] V. M. Kotov, A. S. Dudko, V. I. Suprunov et al., "Nuclear reactors with highly effective fuel cycle," Scientific Report 0210RK00486, Institute of atomic energy of National Nuclear Center Republic Kazakhstan (DSE IAE RSE NNC RK), Kurchatov, Kazakhstan, 2009.

[5] V. M. Kotov, "Application of a volumetric neutron source to enhance the use of raw materials in nuclear power from thermal reactors," Plasma Devices and Operations, vol. 15, no. 3, pp. 219224, 2007.

[6] MCNP/5, "General Monte Carlo N-Particle Transport Code," Version 5, 2003. 

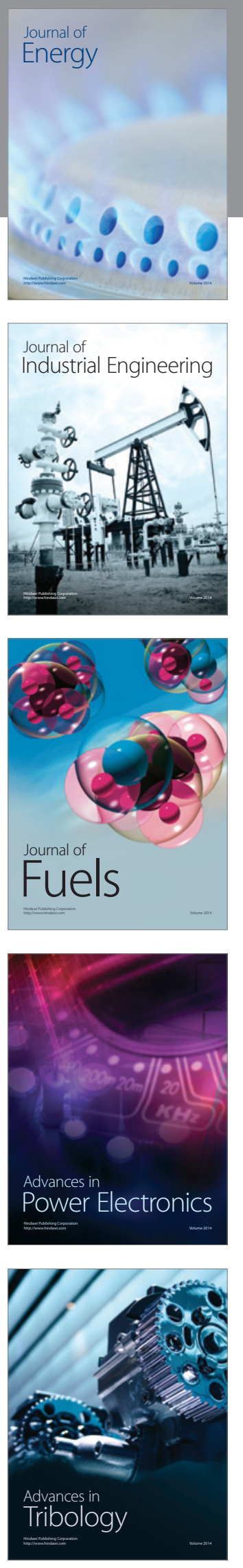
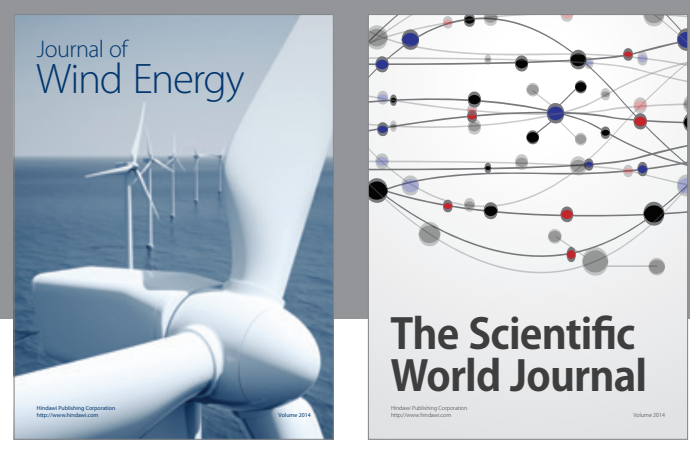

The Scientific World Journal

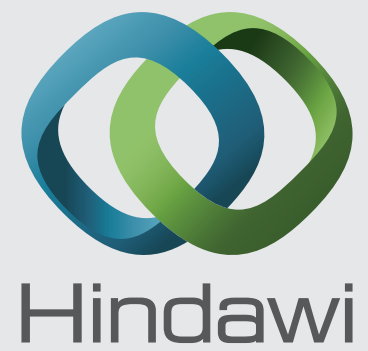

Submit your manuscripts at http://www.hindawi.com
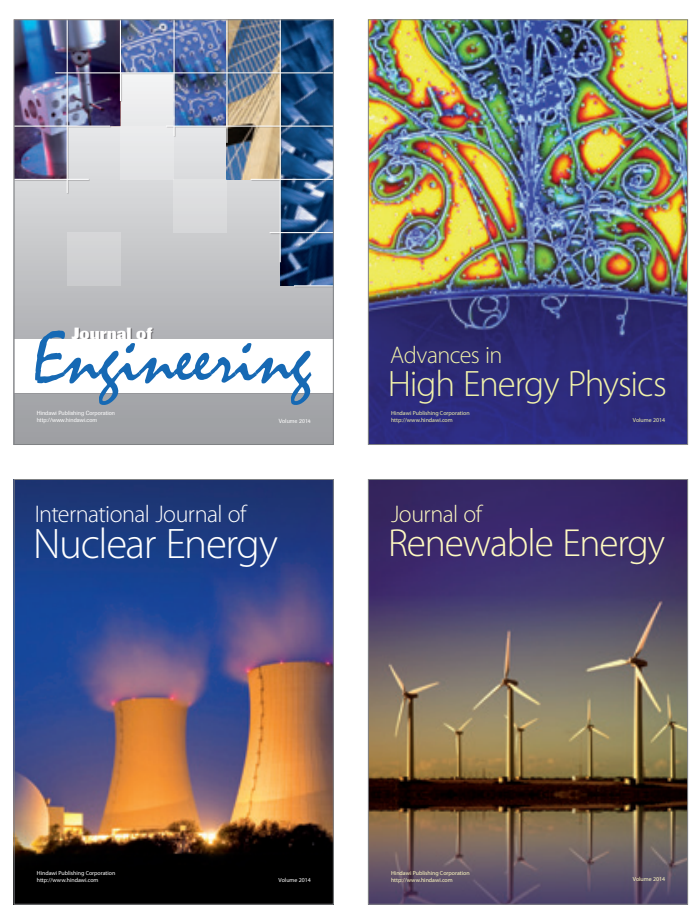

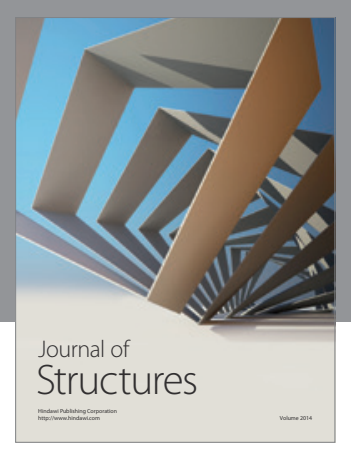

Rotating
Mechinery
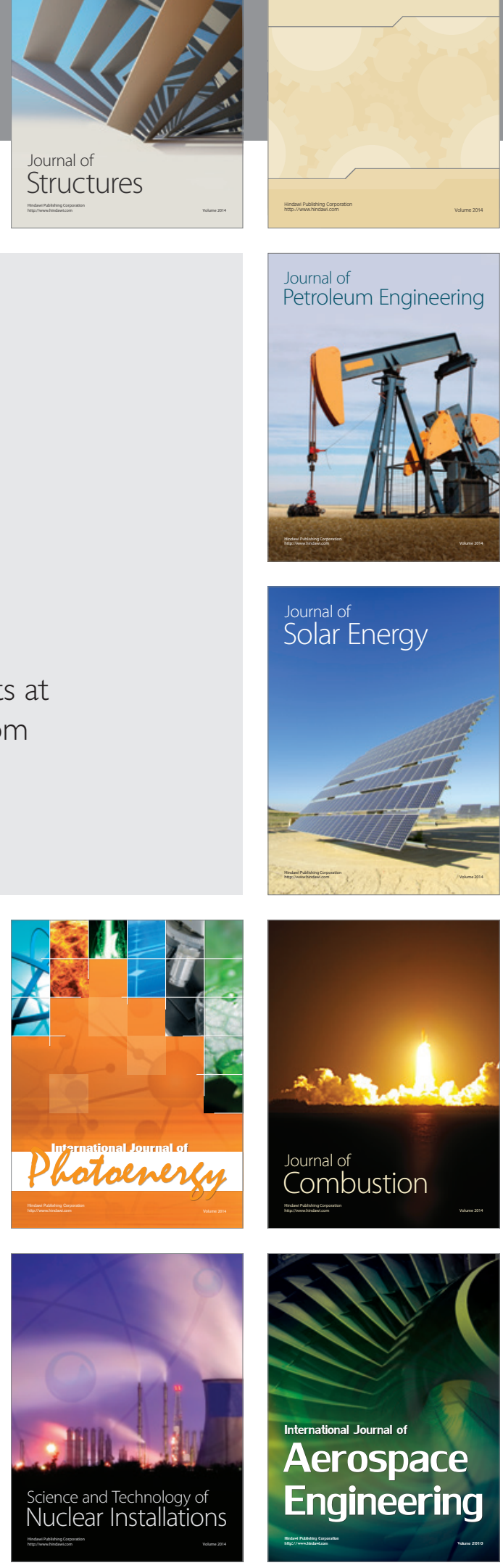